\title{
ANALISIS HUBUNGAN PENGETAHUAN DAN SIKAP TENAGA KESEHATAN DENGAN PENERAPAN SISTEM MANAJEMEN KESEHATAN DAN KESELAMATAN KERJA RUMAH SAKIT DI RSU SEMBIRING DELI TUA TAHUN 2020
}

\author{
Ripai Siregar ${ }^{1}$, Ribka Flora Panjaitan $^{2}$,Andri Lesmana $^{3}$ \\ Institut Kesehatan Deli Husada DeliTua \\ e-mail :ripaisiregar1994@gmail.com
}

\begin{abstract}
:
Hospital Occupational Health and Safety Management (SMK3RS) as an activity process that begins with the planning, organizing, implementing and controlling stages aimed at cultivating occupational health and safety in the hospital. This Health and Safety management system is a manifestation of the hospital's obligations to the rights of health workers that must be fulfilled. The formulation of the problem in this study is how the implementation and internal regulation of the hospital in the implementation of the hospital work health and safety management system, and how the factors that support and hinder its implementation. This type of research is an explanatory research approach. Population is all health workers as many as 399 people and up to 80 people in hospital Sembiring Deli tua.The Data were collection through questionnaires and action observations. Univariate and bivariate data were analyzed by using chi-square, while multivariate data used multiple linear regression tests at significance level of $95 \%$. The results of the study showed that the implementation of implementation of the Hospital Occupational Safety and Health Management System (HOSHMS), was ineffective (52.2\%) and effective $(47,5 \%)$. The results of the test show all of the above independent variables related to the application of implementation of the Hospital Occupational Safety and Health Management System (HOSHMS). The knowledge is the most dominant variable with a coefficient of 0.013 with $\operatorname{Exp}(B) 4,05195 \%$ CI $(1,348-12,175)$. To optimize the application of implementation of the Hospital Occupational Safety and Health Management System (HOSHMS), it is recommended that management continue to be continuously committed in providing resources; implementing a bottom-up system in planning and implementation; improve all forms of communication .
\end{abstract}

Keywords: Knowledge, Attitudes, implementation of the Hospital Occupational Safety and Health Management System

\section{PENDAHULUAN}

Kondisi tersebut dari tahun ke tahun terus membaik, hal ini dapat dilihat dari data Kemenaker trans pada tahun 2009 jumlah perusahaan yang memperoleh penghargaan sertifikat SMK3 berjumlah
150 perusahaan dan pada tahun 2010 jumlah meningkat menjadi 192 perusahaan. Sehingga dari tahun 1997 sampai dengan tahun 2010 jumlah totalnya sudah mencapai 1.492 perusahaan. Selanjutnya pada tahun 2012 terdapat sebanyak 739. Berbagai upaya tersebut 
diterapkan melalui peraturan dan standar K3 baik di dunia internasional maupun nasional. Adapun beberapa peraturan dan standar K3 di duniai nternasional saat ini meliputi: konvensi International Labour Organization (ILO) Nomor 167 Tahun 1988 tentang Safetyand Health in Construction, rekomendasi ILO Nomor 175 Tahun1988 tentang Safetyand Health in Construction, dan ILO June 2001 tentang Guidelines Occupational Healthand

Safety

Manajement

Systems

(OHSMS).

Berdasarkan data PT Jamsostek Provinsi wilayah I, jumlah kasus kecelakaan kerja di Sumatera Utara tahun 2010 cabang Medan sebanyak 944 kasus kecelakaan kerja, sedangkan sepanjang tahun 2012 telah terjadi kecelakaan kerja 2062 kasus dan berdasarkan data Agustus 2013 telah terjadi 1197 kecelakaan Kerja. (Suaraburuh, 2015). Dalam hal klasifikasi kondisi kerja ditemukan bahwa kecelakaan dengan alat pengaman tidak sempurna mencapai angka yang cukup dominan yaitu $78.87 \%$ dan kecelakaan dengan menggunakan peralatan tidak seharusnya mencapai $6.21 \%$. Sementara untuk klasifikasi berdasarkan sumber kecelakaan dengan menggunakan mesin ( press, bor dan gergaji) mendominasi angka $39.88 \%$.

Data laporan K3 RSU Sembiring Deli Tua menunjukkan sebanyak 12 petugas pelaksana mengalami KAK sepanjang tahun 2018 dengan rincian sebagai berikut: 3 perawat, 1 dokterumum, dan 1 petugas laboratorium mengalami Kecelakaan Lalu Lintas (KLL) ketika pergi atau pulang bekerja, 1 petugas gizi tersiram air panas tersiram air panas, 1 petugas teknisi tertimpa tabung oksigen, 2 petugas cleaning service tertimpa tempat tidur dan 5 petugas rekam medis terpeleset. Data laporan terkait gangguan kesehatan, terdapat 480 kasus rawat jalan dengan penyakit terbanyak adalah Infeksi
Saluran Pernafasan Akut (ISPA) dan 90 kasus lainnya di rawat inap dengan penyakit terbanyak adalah dyspepsia (RSU Sembiring 2018).

\section{METODE}

Penelitian ini dilakukan di Rumah Sakit Umum Sembiring Kec. Deli Tua Kab. Deli Serdang. Penelitian ini dilaksanakan mulai Bulan Januari sampai Bulan April Tahun 2019 Jenis penelitian yang digunakan dalam penelitian ini adalah penelitian explanatory dengan pendekatan survey dengan menggunakan analisis multivariat regresi logistik. Teknik sampling yangdigunakan adalah Pengambilan sampel yang digunakan adalah teknik Simple Random Sampling sampel yang berjumlah 80 orang

\section{HASIL DAN PEMBAHASAN}

\section{Karakteristik Responden}

Dalam penelitian ini meliputi umur, jenis kelamin, pendidikan lama bekerja, profesi, sosialisasi responden. Hasil angket kemudian dinyatakan dalam bentuk tabel 1 berikut ini.

Tabel 1.

\begin{tabular}{llcc}
\hline No & Umur & F & $\begin{array}{c}\text { Persentase } \\
(\mathbf{\%})\end{array}$ \\
\hline 1 & $20-30$ Tahun & 45 & 56,3 \\
2 & $31-40$ Tahun & 20 & 25,0 \\
3 & $>41$ Tahun & 15 & 18,7 \\
\hline \multicolumn{2}{l}{ Total } & $\mathbf{8 0}$ & $\mathbf{1 0 0}$ \\
\end{tabular}

\begin{tabular}{llcc}
\hline No & \multicolumn{1}{c}{ Profesi } & F & $\begin{array}{c}\text { Persentase } \\
(\mathbf{\%})\end{array}$ \\
\hline 1 & Dokter umum & 2 & 2,4 \\
2 & Dokter Spesialis & 7 & 8,8 \\
3 & Bidan & 9 & 11,3 \\
4 & Perawat & 35 & 43,8
\end{tabular}




\begin{tabular}{|c|c|c|c|c|c|}
\hline 5 & \multicolumn{2}{|c|}{ Petugas Gizi } & 2 & & 2,5 \\
\hline 6 & \multicolumn{2}{|c|}{$\begin{array}{l}\text { Petugas } \\
\text { Laboratorium }\end{array}$} & 3 & & 3,8 \\
\hline 7 & \multicolumn{2}{|c|}{$\begin{array}{l}\text { Petugas } \\
\text { Radiologi }\end{array}$} & 2 & & 2,5 \\
\hline 8 & \multicolumn{2}{|c|}{$\begin{array}{l}\text { Petugas Rekam } \\
\text { Medis }\end{array}$} & 1 & & 1,3 \\
\hline 9 & \multicolumn{2}{|l|}{ Petugas } & 7 & & 8,8 \\
\hline 10 & \multicolumn{2}{|c|}{$\begin{array}{l}\text { Petugas } \\
\text { Faioterapi }\end{array}$} & 2 & & 2,5 \\
\hline 11 & \multicolumn{2}{|c|}{ Petugas K3 } & 1 & & 1,3 \\
\hline 12 & \multicolumn{2}{|c|}{ Adminstrasi } & 9 & & 11,3 \\
\hline \multicolumn{3}{|c|}{ Jumlah } & 80 & \multicolumn{2}{|c|}{100} \\
\hline $\mathbf{N}$ & \multicolumn{2}{|c|}{ Lama Bekerja } & $\mathbf{F}$ & \multicolumn{2}{|c|}{$\begin{array}{c}\text { Persentase } \\
(\%)\end{array}$} \\
\hline 1 & \multicolumn{2}{|c|}{ 1-2 Tahun } & 25 & \multicolumn{2}{|c|}{31,3} \\
\hline 2 & \multicolumn{2}{|c|}{ 3-4 Tahun } & 40 & \multicolumn{2}{|r|}{50,0} \\
\hline 3 & \multicolumn{2}{|c|}{ >5 Tahun } & 15 & \multicolumn{2}{|r|}{18,7} \\
\hline \multicolumn{2}{|c|}{ Jumlah } & & 80 & \multicolumn{2}{|r|}{100} \\
\hline \multirow[b]{2}{*}{ No } & \multirow[t]{2}{*}{ Variabel } & \multirow[t]{2}{*}{$P_{\text {value }}$} & $\boldsymbol{P R}$ & \multicolumn{2}{|c|}{ CI 95\% } \\
\hline & & & & $\begin{array}{c}\text { Low } \\
\text { er }\end{array}$ & $\begin{array}{c}\text { Lowe } \\
r\end{array}$ \\
\hline 1 & $\begin{array}{l}\text { Pengetahu } \\
\text { an }\end{array}$ & 0.004 & 4.12 & 1.53 & 11.07 \\
\hline 2 & Sikap & 0.008 & $\begin{array}{l}3.61 \\
0\end{array}$ & $\begin{array}{l}1.41 \\
9\end{array}$ & 9.179 \\
\hline
\end{tabular}

\begin{tabular}{llcc}
\hline No & Sosialisasi & F & $\begin{array}{c}\text { Persentase } \\
(\%)\end{array}$ \\
\hline 1 & Tidak Dilakukan & 65 & 81,7 \\
2 & Dilakukan & 15 & 18,3 \\
\hline Jumlah & $\mathbf{8 0}$ & $\mathbf{1 0 0}$ \\
\hline
\end{tabular}

Dari data sampel 80 orang yang diteliti tenaga Kesehatan mayoritas berumur 20-30 tahun sebanyak 45 orang $(56,6 \%)$ dan perempuan sebanyak 60 orang $(75 \%)$, dengan pendidikan terakhir mayoritas sarjana + ners berjumlah 57 orang $(71,3 \%)$, dengan profesi paling banyak adalah perawat sebanyak 35 orang $(48,3 \%)$, tidak dilakukan mengikuti sosiaisasi sebanyak 65 orang $(81,7 \%)$.

\section{Tabel 2 Data Univariat}

\section{Pengetahuan}

Pengetahuan merupakan segala sesuatau

Tabel 2.

\begin{tabular}{ccc}
\hline Pengetahuan & F & $\begin{array}{c}\text { Persentase } \\
(\%)\end{array}$ \\
\hline Kurang & 50 & 62,5 \\
Baik & 30 & 37,5 \\
\hline Total & $\mathbf{8 0}$ & $\mathbf{1 0 0}$ \\
\hline
\end{tabular}

\begin{tabular}{ccc} 
2.Sikap & & \\
\hline Sikap & F & $\begin{array}{c}\text { Persentase } \\
(\%)\end{array}$ \\
\hline Kurang & 44 & 55,0 \\
Baik & 36 & 45,0 \\
\hline Total & $\mathbf{8 0}$ & $\mathbf{1 0 0}$ \\
\hline
\end{tabular}

Dari tabel 2 bahwa dari 80 sampel mayoritas berpengetahuan kurang sebanyak 50 orang $(60,2 \%)$, dan sikap yang paling banyak sikap kurang baik sebanyak 44 orang $(55,0 \%)$, sedangkan penerapan SMK3RS dengan tertinggi tidak. efektif sebanyak 42 orang (52,5\%).

TABEL 3. Analisis Bivariat

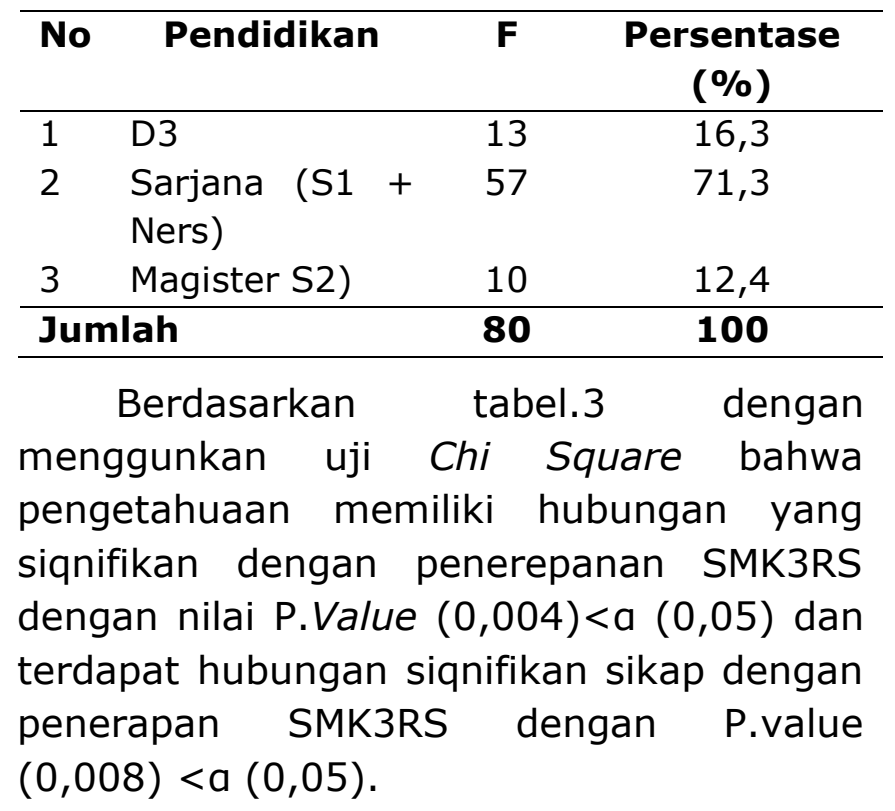




\section{PEMBAHASAN}

Dari 80 responden yang menyatakan pengetahuan kurang dengan penerapan SMK3RS yang efektif sebanyak 20 orang $(25,0 \%)$ dan yang menyatakan ada hubungan pengetahuan kurang dengan penerapan SMK3RS tidak efektif sebanyak 30 orang $(37,5 \%)$. Sedangkan responden yang menyatakan ada hubungan pengetahuan baik dengan penerapan SMK3RS Efektif sebanyak 22 orang $(27,5 \%)$ dan yang menyatakan ada Hubungan pengetahuan Baik dengan Penerapan SMK3RS tidak efektif sebanyak 8 orang $(10,0 \%)$ dengan nilai $P_{\text {value }}$ adalah 0.008 . Berdasarkan hasil tersebut, maka dapat disimpulkan bahwa terdapat hubungan pengetahuan dengan penerapan SMKRS di Rumah Sakit Umum Sembiring Kecamatan Deli Tua Kabupaten Deli Serdang Tahun 2019.

Penelitian ini sejalan dengan hasil penelitian yang dilakukan oleh Pranajaya, dkk (2013) yang menyatakan bahwa ada ini justrumenunjukkan terdapat hubungan antara pengetahuan terhadap penerapan SMK3RS di RSU. Mitra Medika Medan dengan nilai $p<0,05$. Rumah sakit merupakan tempat kerja yang unik dan kompleks, tidak saja menyediakan pelayanan kesehatan bagi masyarakat, tetapi juga merupakan tempat pendidikan dan penelitian kedokteran. Semakin luas pelayanan kesehatan dan fungsi suatu rumah sakit maka semakin kompleks peralatan dan fasilitasnya. Kerumitan yang meliputi segala hal tersebut menyebabkan rumah sakit mempunyai potensi yang bahaya yang sangat besar, tidak hanya bagi pasien dan tenaga medis, risiko ini juga membahayakan pengunjung rumah sakit tersebut.

Hasil laporan National Safety Council (NSC) tahun 1988 menunjukkan bahwa terjadinya kecelakaan di rumah sakit $41 \%$ lebih besar dari pekerja di industri lain. Kasus yang sering terjadi adalah tertusuk jarum, terkilir, sakit pinggang, tergores/terpotong, luka bakar, dan penyakit infeksi, dan sebagainya. Sejumlah kasus dilaporkan mendapatkan kompensasi pada pekerja rumah sakit yaitu sprains, strains: 52\%; contussion, crushing, bruising: 11\%; cuts, laceration, puncture: 10,8\%; fractures: 5,6\%; multiple injuries: $2,1 \%$; thermal burns: $2 \%$; scratches, abrasions: $1,9 \%$; infections: $1,3 \%$; dermatitis : 1,2\%; dan lain-lain: 12,4\% (US Departement of Laboratorium, Bureau of Laboratorium Statistics, 1983)

Khusus di Indonesia, data penelitian sehubungan dengan bahaya-bahaya di rumah sakit belum terganbar dengan jelas namun diyakini bahwa banyak keluhankeluhan dari para petugas di rumah sakit, sehubungan dengan bahaya-bahaya yang ada di rumah sakit. Selain itu, Gun (1983) memberikan catatan bahwa terdapat beberapa kasus penyakit kronis yang diderita petugas rumah sakit, yaitu hipertensi, varises, anemia (kebanyakan wanita), penyakit ginjal dan saluran kemih (69\% wanita), dermatitis dan urtikaria (57\% wanita), serta nyeri tulang belakang dan pergeseran discus intervertebrae. Ditambahkan juga bahwa terdapat beberapa kasus penyakit akut yanng diderita petugas rumah sakit lebih besar 1,5 kali dari petugas atau pekerja lain, yaitu penyakit infeksi dan parasit, saluran pernapasan, saluran cerna, dan keluhan lain seperti sakit telinga, sakit kepala, gangguan saluran kemih, masalah kelahiran anak, gangguan pada saat kehamilan, penyakit kulit dan sistem otot dan tulang rangka.

Manajemen Kesehatan dan Keselamatan Kerja Rumah Sakit (SMK3RS) sebagai suatu proses kegiatan yang dimulai dengan tahap perencanaan, pengorganisasian, pelaksanaan dan 
pengendalian yang bertujuan untuk membudayakan Kesehatan dan Keselamatan kerja di rumah sakit. Sistem manajemen Kesehatan dan Keselamatan ini menjadi salah satu wujud kewajiban rumah sakit terhadap hak tenaga kesehatan yang harus dipenuhi. Rumusan masalah dalam penelitian ini adalah bagaimana pelaksanaan dan pengaturan internal rumah sakit dalam pelaksanaan sistem manajemen kesehatan dan keselamatan kerja rumah sakit, dan bagaimana faktor yang mendukung serta mengambat pelaksanaannya

Metode penelitian Yuridis Sosiologis, dengan spesifikasi penelitian deskriptif analitik. Bertujuan untuk megetahui gambaran dan identifikasi tentang pelaksanaan Sistem Manajemen Kesehatan dan Keselamatan Kerja (SMK3), pelaksanaan Sistem Manajemen Kesehatan dan Keselamatan Kerja (SMK3), dan faktor yang mendukung serta menghambat pelaksanaan Sistem Manajemen Kesehatan dan Keselamatan Kerja (SMK3) di Rumah Sakit Umum Roemani Semarang kemudian menganalisis berdasarkan pengaturan tentang Sistem Managemen Kesehatan dan Keselamatan Kerja Rumah Sakit (SMK3RS).

Hasil penelitian dengan responden Rumah Sakit Umum Roemani yang terdiri dari Direksi, Petugas K3RS, Dokter, Bidan dan Perawat, bahwa pengaturan internal tentang pelaksanaan SMK3RS diatur dalam bentuk kebijakan teknis operasional yang berupa Surat Keputusan dari Direktur. Pelaksanaan Manajemen Kesehatan dan Keselamatan Kerja (SMK3) Rumah Sakit Umum Roemani belum sepenuhnya dilaksanakan sesuai dengan peraturan terkait. Faktor pendukung dalam pelaksanaan K3RS di Rumah Sakit Umum Roemani adalah adanya kebijakan, sarana dan prasarana yang menunjang untuk pelaksanaan K3RS. Faktor penghambat dalam pelaksanaan K3RS adalah belum tersosialosainya program kerja pada anggota organisasi dan karyawan, sehingga pelaksanaan K3RS belum terkoordinasikan, pelaksanaan K3RS baru terbentuk sehingga pelaksanaan K3 masih berada di masing - masing unit, evaluasi belum terlaksana secara menyeluruh

\section{KESIMPULAN}

Kesimpulan yang dapat ditarik dari penelitian ini adalah sebagai berikut:

1.Terdapat hubungan yang signifikan antara pengetahuan tenaga kesehatan dengan penerapan sistem manajemen keselamatan dan kesehatan kerja rumah sakit (SMK3RS).

2.Terdapat hubungan yang signifikan antara sikap tenaga kesehatan dengan penerapan sistem manajemen keselamatan dan kesehatan kerja rumah sakit (SMK3RS).

3.Variabel yang valing dominan serta paling berhubungan adalah variabel pengetahuan tenaga kesehatan dengan penerepan SMK3RS di RSU Sembiring Deli Tua Kab. Deli Serdang.

\section{DAFTAR PUSTAKA}

Alfred Billy Wuon, (2013). Jurnal Analis Penerapan Sistem Manajemen Keselamatan dan Kesehatan Kerja di PT. Karismas WitikcoMakmur. Bitung. 2013.

Agiviana, A. P. 2015. Analisis Pengaruh Persepsi, Sikap, Pengetahuan dan Tempat Kerja Terhadap Perilaku Keselamatan Karyawan (Studi pada Perusahaan PT. Mulia Glass Container Division). Diunduh tanggal 2 Juni 2016.Tersedia:http://eprints.undip.ac. id/45720/1/12_AGIVIANA.pdf. 
Depkes RI, 2009, Standar Kesehatan dan Keselamatan Kerja Di Rumah Sakit (K3RS), Jakarta : Departemen Kesehatan RI.

Efendi, Lutfi, 2003, Pokok Pokok Hukum Administrasi, Malang : Bayumedia Publishing.

Hariyono, Widodo, 2014, Analisis Kesiapan Menghadapi Akreditasi Pada Pelayanan Administrasi Dan Manajemen Di Rumah Sakit Umum Rajawali Citra Kabupaten Bantul (Telaah Pembanding Pada Akreditasi Rumah Sakit Bidang Pelayanan K3B), Jurnal Kesehatan Masyarakat, Volume7.

HR, Ridwan, 2013, Hukum Administrasi Negara, Jakarta :Rajawali Pers.

Indriarti S, Maria Farida 2007. Ilmu PerUndang-undangan Jenis Fungsi dan Materi Muatan. Yogyakarta: Kanisius.

Ivana, Azza, 2014, Analisa Komitmen Manajemen Rumah Sakit (RS) Terhadap Keselamatan dan Kesehatan Kerja (K3) pada RS Prima Medika Pemalang, Jurnal Kesehatan Masyarakat, Volume 2.

Joint Commission International Accreditation Standards For Hospital $5^{\text {th }}$ Edition, 2014.

Kementerian Kesehatan RI, 2002, Pedoman Peraturan Internal Rumah sakit.

Kementrian kesehatan. 2005.No. 496 Tentang Pedoman Audit Medis Di Rumah Sakit. Jakarta: Kepmenkes RI.

ILO 2013. Keselamatan Dan Kesehatan Kerja Di Tempat Kerja. Modul 5. Jakarta: International Labour Office.
Kementrian Kesehatan. 2009. No 44 Tentang Rumah Sakit.Jakarta: Departemen kesehatan RI.

Nazir, Muhammad. 2003. Metode Penelitian. Jakarta: Ghalia Indonesia. 